\title{
No association between BDNFVal66Met polymorphism and treatment response in obsessive-compulsive disorder in the Japanese population
}

\author{
This article was published in the following Dove Press journal: \\ Neuropsychiatric Disease and Treatment \\ II March 2016 \\ Number of times this article has been viewed
}

\author{
Hidehiro Umehara' \\ Shusuke Numata' \\ Makoto Kinoshita' \\ Shinya Watanabe' \\ Shutaro Nakaaki \\ Satsuki Sumitani ${ }^{1,3}$ \\ Tetsuro Ohmori' \\ 'Department of Psychiatry, Institute \\ of Biomedical Sciences, Tokushima \\ University Graduate School, \\ Tokushima, ${ }^{2}$ Laboratory of Aging, \\ Behavior and Cognition, Department \\ of Neuropsychiatry, Keio University \\ School of Medicine, Tokyo, ${ }^{3}$ Academic \\ Support Office for Students with \\ Special Needs, Tokushima University, \\ Tokushima, Japan
}

\begin{abstract}
Aim: Brain-derived neurotrophic factor (BDNF) is a member of the neurotrophin family, and it promotes the development and function of dopaminergic and serotonergic neurons. The Met allele of the $B D N F$ Val66Met polymorphism is associated with a decrease in activity-dependent secretion of BDNF compared with the Val allele, and a number of studies have provided evidence for the association between this polymorphism and obsessive-compulsive disorder (OCD). The purpose of this study was to investigate whether this functional variant of the $B D N F$ gene is associated with OCD and treatment response in patients with OCD in the Japanese population.

Methods: We first performed a case-control association study between the BDNF Val66Met polymorphism and OCD (175 cases and 2,027 controls). Then, we examined an association between this polymorphism and treatment response in 96 patients with OCD.

Results: We found no significant association between the Met allele and OCD risk or between the Met allele and treatment responses to selective serotonin reuptake inhibitors or serotonin reuptake inhibitor with an atypical antipsychotic $(P>0.05)$.

Conclusion: Our results suggest that the $B D N F$ Val66Met polymorphism may not be associated as a risk factor for developing OCD or with therapeutic response in patients with OCD in the Japanese population.
\end{abstract}

Keywords: obsessive-compulsive disorder, BDNF, treatment response, association study, SSRI, atypical antipsychotic

\section{Introduction}

Obsessive-compulsive disorder (OCD) is a neuropsychiatric disorder with a prevalence of $\sim 2 \%$, and it is characterized by repetitive, persistent, intrusive thoughts and repetitive, compulsive behaviors. ${ }^{1}$ Serotonin reuptake inhibitors (SRIs) and antipsychotics are used as pharmacological treatments for $\mathrm{OCD},{ }^{2,3}$ suggesting that changes of serotonergic and dopaminergic neurotransmissions may be related to OCD.

Brain-derived neurotrophic factor (BDNF) is a member of the neurotrophin family, which is known to regulate many aspects of neural circuit development and function, including cell proliferation and differentiation, axon and dendrite growth, synaptogenesis, and synaptic function and plasticity. ${ }^{4,5}$ Substantial evidence suggests that BDNF promotes the development and function of dopaminergic and serotonergic neurons. ${ }^{6,7}$ Several studies have demonstrated that patients with OCD had significantly decreased plasma and serum BDNF levels compared with controls, ${ }^{8-12}$ and the administration of selective SRIs (SSRIs) and atypical antipsychotics enhances BDNF gene expression. ${ }^{6,13}$
Correspondence: Shusuke Numata Department of Psychiatry, Institute of Biomedical Sciences, Tokushima University Graduate School, 3-8-15 Kuramoto-cho, Tokushima 770-8503, Japan

Tel $+8|886337| 30$

Fax $+8|886337| 3 \mid$

Email shu-numata@umin.ac.jp
Neuropsychiatric Disease and Treatment 2016:12 6II-6I5

Dovepress

http://dx.doi.org/10.2147/NDT.S102100 (c) (1) (5) 2016 Umehara et al. This work is published and licensed by Dove Medical Press Limited. The full terms of this license are available at https://www.dovepress.com/terms.php (c) hereby accept the Terms. Non-commercial uses of the work are permitted without any further permission from Dove Medical Press Limited, provided the work is properly attributed. For permission for commercial use of this work, please see paragraphs 4.2 and 5 of our Terms (https://www.dovepress.com/terms.php). 
The BDNF Val66Met polymorphism (rs6265) is a functional polymorphism, which affects intracellular processing and secretion of BDNF, with the Met allele being associated with a decrease in activity-dependent secretion of BDNF compared with the Val allele. ${ }^{14,15}$ This polymorphism has been extensively investigated in patients with OCD, and a number of studies have provided evidence for association between this polymorphism and OCD. For example, one family-based association study and four case-control studies have demonstrated that the $B D N F$ Val66Met polymorphism might be genetically involved in the etiology of OCD, ${ }^{16-20}$ although a recent meta-analysis of genetic association studies failed to support these findings. ${ }^{21}$ In addition, several studies have demonstrated that the $B D N F$ Val66Met polymorphism was associated with clinical characteristics of OCD, such as symptom severity, age of onset, family history, poor executive functions, and impairments in decision making. 16,18,22,23 Furthermore, the $B D N F$ Val66Met polymorphism was associated with treatment response to exposure-based cognitive-behavior therapy in patients with $\mathrm{OCD},{ }^{24}$ and a $B D N F$ haplotype, including the $B D N F$ Val66Met polymorphism, was associated with treatment response to antidepressants in patients with OCD. ${ }^{25}$

In this study, we hypothesized that the $B D N F$ Val66Met polymorphism would be involved in the pathophysiology as well as treatment response of OCD in the Japanese population. We first performed a case-control association study to determine whether the $B D N F$ Val66Met polymorphism was genetically implicated in patients with OCD (175 cases and 2,027 controls). Then, we investigated whether this functional polymorphism was associated with the treatment response in 96 patients with OCD.

\section{Subjects and methods Subjects}

A total of 175 patients with OCD (82 males and 93 females, mean age: $33.7 \pm 10.9$ years) were recruited from the Tokushima University Hospital and Yagoto Hospital in Japan in the South Island of Japan (Shikoku) and Yagoto Hospital at Middle West in the Mainland of Japan. All patients were of Japanese descent. The diagnosis of OCD was made according to the Diagnostic and Statistical Manual of Mental Disorders (DSM-IV) criteria by at least two expert psychiatrists on the basis of extensive clinical interviews and a review of medical records. Patients comorbid with other axis I disorders were excluded. Among the 175 patients with OCD, 96 patients participated in the present pharmacogenetic study. These patients were divided into three groups according to the treatment response evaluated by the Yale Brown ObsessiveCompulsive Scale (Y-BOCS) as follows: SSRI (fluvoxamine, paroxetine, sertraline, or escitalopram) responders as group A (N=56); SSRI with an atypical antipsychotic augmentation (risperidone, olanzapine, quetiapine, perospirone, or aripiprazole) responders as group $\mathrm{B}(\mathrm{N}=23)$; and nonresponders to either SSRI or SSRI with an atypical antipsychotic augmentation as group $\mathrm{C}(\mathrm{N}=17)$. The treatment responders were defined as patients with a reduction in Y-BOCS $>35 \%$. They were treated in a naturalistic clinical course, and the mean follow-up duration was $12.9 \pm 8.2$ months. Only the patients who had no response to SSRI were treated by adding an atypical antipsychotic drug (group B plus C). There were no significant differences among the three groups in sex, age, onset age, or duration of illness, while significant differences were found in Y-BOCS scores at baseline and at the end of the treatment (Table 1). Most of these samples were used in our previous study. ${ }^{26}$ The control group comprised

Table I Treatment response group and clinical symptoms of patients with obsessive-compulsive disorder

\begin{tabular}{|c|c|c|c|c|c|}
\hline & Group $A(N=56)$ & Group B $(\mathbf{N}=23)$ & Group $C(\mathbf{N}=17)$ & All patient groups & $P$-value \\
\hline \multicolumn{6}{|l|}{ Sex } \\
\hline Male, n (\%) & $26(46.4)$ & $13(56.5)$ & $9(52.9)$ & $48(50)$ & 0.69 \\
\hline Female, n (\%) & $30(53.6)$ & $10(43.5)$ & $8(47.1)$ & $48(50)$ & \\
\hline Age, mean (SD) & $32.86(12.79)$ & $30.39(11.07)$ & $28.53(9.77)$ & 31.5 (II.9) & 0.38 \\
\hline Onset age, mean (SD) & $24.75(\mid 0.7 I)$ & $22.74(12.05)$ & $18.35(10.94)$ & $23.1(11.2)$ & 0.12 \\
\hline Duration of illness, mean (SD) & $8.11(9.14)$ & $7.65(6.29)$ & $10.18(10.19)$ & $8.4(8.6)$ & 0.63 \\
\hline \multicolumn{6}{|l|}{ Y-BOCS score } \\
\hline Baseline, mean (SD) & $23.27(5.04)$ & $25.57(4.5 \mathrm{I})$ & $28.4 \mathrm{I}(4.43)$ & $24.7(5.1)$ & 0.001 \\
\hline After treatment, mean (SD) & $8.20(3.86)$ & II.43 (2.97) & $25.53(4.64)$ & $12.0(7.4)$ & $<0.001$ \\
\hline
\end{tabular}

Notes: $P$-values are calculated by $\chi^{2}$ and ANOVA. Duration of illness measured as the length from the onset of obsessive-compulsive disorder to start of the treatment in the Tokushima University Hospital. Group A, responders to SSRI; group B, responders to SSRI with an atypical antipsychotic; group C, nonresponders to SSRI with an atypical antipsychotic.

Abbreviations: ANOVA, analysis of variance; SSRI, selective serotonin reuptake inhibitor; Y-BOCS, Yale Brown Obsessive-Compulsive Scale; SD: standard deviation. 
2,027 volunteers (855 males and 1,172 females; mean age: $38.7 \pm 13.3$ years) recruited from hospital staff, students, and company employees who were documented to be free from psychiatric problems with no past history of mental illness. All of them were of Japanese descent. Details can be seen in our previous paper. ${ }^{27}$ The institutional ethics committee of the University of Tokushima Graduate School approved the current study and all subjects signed written, informed consent forms.

\section{Genotyping}

We genotyped the $B D N F$ Val66Met polymorphism (rs6265) by using a commercially available TaqMan probe with the Applied Biosystems 7500 Fast Real Time PCR System and followed the protocol recommended by the manufacturer (Thermo Fisher Scientific, Waltham, MA, USA).

\section{Statistical methods}

The association between rs6265 and OCD and the association between rs6265 and treatment response in patients with OCD were examined using logistic regression under a log-additive model. Odds ratio (OR), 95\% confidence intervals (CIs), and $P$-value were calculated by using R Version 3.1.2. Power calculation was performed using the $\mathrm{G}^{*}$ Power 3.1. ${ }^{28}$

\section{Results}

\section{Association between rs6265 and OCD}

The genotype and allele distributions of rs6265 are shown in Table 2. The genotypic distribution of rs6265 did not deviate significantly from the Hardy-Weinberg equilibrium in the patient group or in the control group $(P>0.05)$. We revealed no significant effect of the Met allele on the OCD risk in our sample set (per-allele OR, 1.05; 95\% CI, 0.84-1.31; $P=0.68$ ).

\section{Association between rs6265 and the treatment response in patients with OCD}

When we compared group A with group B plus C, we did not find a significant association between rs 6265 and the treatment response to SSRI (per-allele OR, 1.43; 95\% CI, 0.78-2.59; $P=0.24)$. When we compared group B with group $\mathrm{C}$, we did not find a significant association between rs6265 and the treatment response to SSRI with an antipsychotic medication (per-allele OR, 1.28; 95\% CI, 0.54-3.03; $P=0.57$ ). When we compared group A plus B with group $\mathrm{C}$, we did not find a significant association between rs6265 and the treatment response to SSRI or SSRI with an antipsychotic medication (per-allele OR, 1.59; 95\% CI, 0.718-3.53; $P=0.25$ ).

The power of our sample size for the treatment response had 0.27 (group A vs group B plus C), 0.14 (group B vs group C), and 0.15 (group A plus B vs group C), respectively, for detecting a significant association $(\alpha<0.05)$ when we applied an OR of 1.4 in the power calculations.

\section{Discussion}

First, we found no significant effect on the Met allele of the $B D N F$ Val66Met polymorphism on the OCD risk. This is the first association study between the $B D N F$ Val66Met polymorphism and OCD conducted on a Japanese population. Our finding is consistent with the results of two meta-analyses of previous genetic association studies ${ }^{21,29}$ and with the results of two genome-wide association studies. ${ }^{30,31}$ Zai et al conducted a meta-analysis of 13 genetic association studies (five familybased association studies and eight case-control studies, which included Caucasian, Turk, Mexican, and South African Afrikaner cohorts), and they found no association between the $B D N F$ Val66Met polymorphism and OCD (allele OR, 1.09; 95\% CI, 0.99-1.21; $P=0.09) .{ }^{21}$ Mattheisen et al conducted a genome-wide association studies $(\mathrm{N}=5,061)$, and they did not find the BDNF Val66Met polymorphism among the top 33 single-nucleotide polymorphisms (SNPs) with $P<1 \times 10^{-5} \cdot{ }^{30}$ However, caution must be exercised, because the sample size of each association study, including our study, was small, and the allele frequency of this polymorphism is dependent on ethnic background. ${ }^{32}$

Second, we demonstrated that the $B D N F$ Val66Met polymorphism was not associated with treatment responses to SSRI in patients with OCD. This result is consistent with the result of a previous pharmacogenetic association study of $B D N F$ variants in patients with $\mathrm{OCD}^{25}$ and the result of a genome-wide association study of treatment response in patients with OCD. ${ }^{33}$ Real et al compared a group of good responders with a group of poor responders to SRIs (fluoxetine, fluvoxamine, or clomipramine) in patients

Table 2 Genotype and allele distributions in subjects with obsessive-compulsive disorder and control subjects

\begin{tabular}{llllllllll}
\hline Subject group & Subjects $(\mathbf{n})$ & Val/Val $(\mathbf{n})$ & Val/Met $(\mathbf{n})$ & Met/Met $(\mathbf{n})$ & Val $(\mathbf{n})$ & Met $(\mathbf{n})$ & HWE & OR $(95 \% \mathrm{Cl})$ & $\mathbf{P}$-value \\
\hline OCD & 175 & 59 & 83 & 33 & 201 & 149 & 0.69 & $1.05(0.84-1.31)$ & 0.68 \\
Control & 2,027 & 686 & 1,002 & 339 & 2,374 & 1,680 & 0.40 & & \\
\hline
\end{tabular}

Abbreviations: $\mathrm{Cl}$, confidence interval; HWE, Hardy-Weinberg equilibrium; Met, methionine; OCD, obsessive-compulsive disorder; OR, odds ratio; Val, valine. 
with OCD for 12 weeks $(\mathrm{N}=123)$, and they did not find a significant association between the BDNF Val66Met polymorphism and clinical response, although they did reveal significant differences between nonresponders and responders in the haplotype-based analysis of four SNPs (rs1103009, rs 10501087, rs6265, and rs1491850). ${ }^{25}$ Qin et al conducted a genome-wide association analysis of SRI response in 804 patients with OCD, and they could not find the BDNF Val66Met polymorphism among the top 42 SNPs with $P<1 \times 10^{-4}$. $^{33}$ However, the follow-up periods (12.9 months vs 12 weeks vs lack of detailed information), SRI medications, and definitions of treatment response (based on Y-BOCS vs based on self-report) differed among these three studies.

Finally, we demonstrated that the BDNF Val66Met polymorphism was not associated with treatment response to SSRI with an atypical antipsychotic in patients with OCD. This is the first pharmacogenetic study to evaluate the effect of $B D N F$ Val66Met polymorphism on treatment response to SSRI with an atypical antipsychotic in patients with OCD. However, our sample size was small, and our patients were treated with a variety of SSRI and atypical antipsychotics. Further replication studies using larger samples with unified medications will be needed.

\section{Conclusion}

In conclusion, the $B D N F$ Val66Met polymorphism may not be associated as a risk factor for developing OCD or the therapeutic responses to SSRI or to SSRI with an atypical antipsychotic, in patients with OCD in the Japanese population.

\section{Acknowledgments}

The authors would like to thank all the volunteers who understood our study purpose and participated in this study, and the physicians who helped us to collect clinical data and blood samples at the mental hospitals. The authors would also like to thank Mrs Akemi Okada for her technical assistance. This work was supported by Grant-in-Aid for Scientific Research (C) (no 26245678).

\section{Author contributions}

Drs Numata and Ohmori designed the study and acquired the data. Drs Nakaaki, Kinoshita, Sumitani, Watanabe, and Umehara acquired the data, and Dr Umehara analyzed the data. Dr Umehara wrote the first draft of the manuscript. All authors contributed toward data analysis, drafting and critically revising the paper, gave final approval of the version to be published, and agree to be accountable for all aspects of the work.

\section{Disclosure}

The authors report no conflicts of interest in this work.

\section{References}

1. Ruscio AM, Stein DJ, Chiu WT, Kessler RC. The epidemiology of obsessive-compulsive disorder in the National Comorbidity Survey Replication. Mol Psychiatry. 2010;15(1):53-63.

2. Arumugham SS, Reddy JYC. Augmentation strategies in obsessivecompulsive disorder. Expert Rev Neurother. 2013;13(2):187-202.

3. Soomro GM, Altman D, Rajagopal S, Oakley-Browne M. Selective serotonin re-uptake inhibitors (SSRIs) versus placebo for obsessive compulsive disorder (OCD). Cochrane Database Syst Rev. 2008;(1): CD001765.

4. Park H, Poo M. Neurotrophin regulation of neural circuit development and function. Nat Rev Neurosci. 2013;14(1):7-23.

5. Pilakka-Kanthikeel S, Atluri VS, Sagar V, Saxena SK, Nair M. Targeted brain derived neurotropic factors (BDNF) delivery across the blood-brain barrier for neuro-protection using magnetic nano carriers: an in-vitro study. PLoS One. 2013;8(4):e62241.

6. Martinowich K, Lu B. Interaction between BDNF and serotonin: role in mood disorders. Neuropsychopharmacology. 2008;33(1):73-83.

7. Nurjono M, Lee J, Chong S-A. A review of brain-derived neurotrophic factor as a candidate biomarker in schizophrenia. Clin Psychopharmacol Neurosci. 2012;10(2):61-70.

8. Dos Santos IM, Ciulla L, Braga D, et al. Symptom dimensional approach and BDNF in unmedicated obsessive-compulsive patients: an exploratory study. CNS Spectr. 2011;16(9):179-189.

9. Fontenelle LF, Barbosa IG, Luna JV, Rocha NP, Silva Miranda A, Teixeira AL. Neurotrophic factors in obsessive-compulsive disorder. Psychiatry Res. 2012;199(3):195-200.

10. Maina G, Rosso G, Zanardini R, Bogetto F, Gennarelli M, BocchioChiavetto L. Serum levels of brain-derived neurotrophic factor in drug-naïve obsessive-compulsive patients: a case-control study. $J$ Affect Disord. 2010;122(1-2):174-178.

11. Wang Y, Mathews CA, Li Y, Lin Z, Xiao Z. Brain-derived neurotrophic factor (BDNF) plasma levels in drug-naïve OCD patients are lower than those in healthy people, but are not lower than those in drug-treated OCD patients. J Affect Disord. 2011;133(1-2):305-310.

12. Wang Y, Zhang H, Li Y, et al. BDNF Val66Met polymorphism and plasma levels in Chinese Han population with obsessive-compulsive disorder and generalized anxiety disorder. J Affect Disord. 2015; 186:7-12.

13. Hill RA, Du X, Wu Y-WC. BDNF-TrkB signaling as a therapeutic target in neuropsychiatric disorders. J Receptor Ligand Channel Res. 2014;7:61.

14. Chen Z-Y, Patel PD, Sant G, et al. Variant brain-derived neurotrophic factor (BDNF) (Met66) alters the intracellular trafficking and activitydependent secretion of wild-type BDNF in neurosecretory cells and cortical neurons. J Neurosci. 2004;24(18):4401-4411.

15. Egan MF, Kojima M, Callicott JH, et al. The BDNF val66met polymorphism affects activity-dependent secretion of BDNF and human memory and hippocampal function. Cell. 2003;112(2):257-269.

16. Alonso P, Gratacòs M, Menchón JM, et al. Extensive genotyping of the BDNF and NTRK2 genes define protective haplotypes against obsessive-compulsive disorder. Biol Psychiatry. 2008;63(6):619-628.

17. Hall D, Dhilla A, Charalambous A, Gogos JA, Karayiorgou M. Sequence variants of the brain-derived neurotrophic factor (BDNF) gene are strongly associated with obsessive-compulsive disorder. Am J Hum Genet. 2003;73(2):370-376.

18. Hemmings SMJ, Kinnear CJ, Van der Merwe L, et al. Investigating the role of the brain-derived neurotrophic factor (BDNF) val66met variant in obsessive-compulsive disorder (OCD). World J Biol Psychiatry. 2008;9(2):126-134.

19. Márquez L, Camarena B, Hernández S, Lóyzaga C, Vargas L, Nicolini H. Association study between BDNF gene variants and Mexican patients with obsessive-compulsive disorder. Eur Neuropsychopharmacol. 2013;23(11):1600-1605. 
20. Rocha FF, Malloy-Diniz L, Lage NV, Corrêa H. Positive association between MET allele (BDNF Val66Met polymorphism) and obsessivecompulsive disorder. Rev Bras Psiquiatr. 2010;32(3):323-324.

21. Zai G, Zai CC, Arnold PD, et al. Meta-analysis and association of brainderived neurotrophic factor (BDNF) gene with obsessive-compulsive disorder. Psychiatr Genet. 2015;25(2):95-96.

22. Katerberg H, Lochner C, Cath DC, et al. The role of the brain-derived neurotrophic factor (BDNF) val66met variant in the phenotypic expression of obsessive-compulsive disorder (OCD). Am J Med Genet B Neuropsychiatr Genet. 2009;150B(8):1050-1062.

23. Tükel R, Gürvit H, Ozata B, et al. Brain-derived neurotrophic factor gene Val66Met polymorphism and cognitive function in obsessivecompulsive disorder. Am J Med Genet B Neuropsychiatr Genet. 2012; 159B(7):850-858.

24. Fullana MA, Alonso P, Gratacòs M, et al. Variation in the BDNF Val66Met polymorphism and response to cognitive-behavior therapy in obsessive-compulsive disorder. Eur Psychiatry. 2012;27(5):386-390.

25. Real E, Gratacòs M, Soria V, et al. A brain-derived neurotrophic factor haplotype is associated with therapeutic response in obsessivecompulsive disorder. Biol Psychiatry. 2009;66(7):674-680.

26. Umehara H, Numata S, Tajima A, et al. No association between the COMT Val158Met polymorphism and the long-term clinical response in obsessive-compulsive disorder in the Japanese population. Hum Psychopharmacol. 2015;30(5):372-376.
27. Nishi A, Numata S, Tajima A, et al. Meta-analyses of blood homocysteine levels for gender and genetic association studies of the MTHFR C677T polymorphism in schizophrenia. Schizophr Bull. 2014;40(5): 1154-1163.

28. Faul F, Erdfelder E, Buchner A, Lang A-G. Statistical power analyses using $\mathrm{G}^{*}$ Power 3.1: tests for correlation and regression analyses. Behav Res Methods. 2009;41(4):1149-1160.

29. Taylor S. Molecular genetics of obsessive-compulsive disorder: a comprehensive meta-analysis of genetic association studies. Mol Psychiatry. 2013;18(7):799-805.

30. Mattheisen M, Samuels JF, Wang Y, et al. Genome-wide association study in obsessive-compulsive disorder: results from the OCGAS. Mol Psychiatry. 2015;20(3):337-344.

31. Stewart SE, Yu D, Scharf JM, et al. Genome-wide association study of obsessive-compulsive disorder. Mol Psychiatry. 2013;18(7): 788-798.

32. Shimizu E, Hashimoto K, Iyo M. Ethnic difference of the BDNF 196G/A (val66met) polymorphism frequencies: the possibility to explain ethnic mental traits. Am JMed Genet B Neuropsychiatr Genet. 2004;126B(1):122-123.

33. Qin H, Samuels JF, Wang Y, et al. Whole-genome association analysis of treatment response in obsessive-compulsive disorder. Mol Psychiatry. 2016;21(2):270-276.
Neuropsychiatric Disease and Treatment

\section{Publish your work in this journal}

Neuropsychiatric Disease and Treatment is an international, peerreviewed journal of clinical therapeutics and pharmacology focusing on concise rapid reporting of clinical or pre-clinical studies on a range of neuropsychiatric and neurological disorders. This journal is indexed on PubMed Central, the 'PsycINFO' database and CAS,

\section{Dovepress}

and is the official journal of The International Neuropsychiatric Association (INA). The manuscript management system is completely online and includes a very quick and fair peer-review system, which is all easy to use. Visit http://www.dovepress.com/testimonials.php to read real quotes from published authors. 